\title{
Traitors Among Victims: The Case of Market-Community Wildlife Collaborative Management in Malawi's Majete Wildlife Reserve
}

\author{
Sane Pashane Zuka ${ }^{1}$, Brenda-Kanyika Zuka ${ }^{2}$ \\ ${ }^{1}$ Department of Land Economy, University of Malawi, Blantyre, Malawi \\ ${ }^{2}$ Department of History, Catholic University of Malawi, Blantyre, Malawi \\ Email address: \\ spzuka@gmail.com (Sane P. Z.), brendakanyikazuka@gmail.com (Brenda-Kanyika Z.)
}

To cite this article:

Sane Pashane Zuka, Brenda-Kanyika Zuka. Traitors Among Victims: The Case of Market-Community Wildlife Collaborative Management in Malawi's Majete Wildlife Reserve. Advances in Sciences and Humanities. Vol. 2, No. 5, 2016, pp. 40-47. doi: 10.11648/j.ash.20160205.11

Received: September 26, 2016; Accepted: October 28, 2016; Published: December 5, 2016

\begin{abstract}
In line with political moves towards democratic governance, state-based management of wildlife is being replaced by community-market collaborative management approaches. In Malawi, community-market collaboration in wildlife management is particularly presented as a panacea to lack of community support for wildlife conservation due to their exclusion from enjoying the benefits ofits conservation. Community-market collaborative management, however, changes the rules and procedures in accessingthe benefits of wildlife conservation. Using MajeteWildlife Reserve, this study explores theextent to which the new approach addresses past unequal benefits from wildlife conservation, especially for the local communities. The study employed both qualitative (in-depth interviews, focus group discussions) and quantitative (desk study) methods. The findings from Majete Wildlife Reserve reveal that collaborative wildlifemanagement is predominantly a market oriented activity that reproduces newmodes of accessing benefits and new actors that sustains its inherent principles. Consequently, while a few victims of former state-based wildlife management approach are currently benefiting from and have become faithful advocates of the new regime, a number of vulnerable groups of people continue to suffer. At present, community-market collaborative management hastaken the form of patronage rather than partnership. Hence, the solution to inclusive and transparent wildlife management cannot be a matter of just fussing two management approaches.
\end{abstract}

Keywords: Malawi, Community-Market Wildlife Management, Political Ecology, Market System, Collaborative Management

\section{Introduction}

Since the turn of the 1980 s, collaborative management has become a new orthodoxy approach to management of natural resources and wildlife conservation in Africa, including Malawi Zimbabwe, South Africa and Kenya [7, 31]. Its rise is attributed to the overwhelming outcry against the long time state management that de-franchised local communities from enjoying the benefits of wildlife conservation. Collaborative management is justified on the assumption that it would bring efficiency in wildlife management while at the same time taking care of the interests of the community. This paper undertakes a critical review of Malawi's experience with market-community collaboration in wildlife management as a solution to a number of crisis in wildlife conservation [18].
Adams and McShane [2] particularly argues for the involvement of local peoplesin wildlife conservation to counteract conservation costs. This call is in line with a number of authors who have questioned the ability of statebased wildlife management approaches in meeting the needs of the local people $[7,28]$.

The adoption of collaborative wildlife management isgenerally uphold by failure of state conservation to encourage free market operations due to inappropriate rights and arrangements; and the criticisms raised against the market approach $[2,28]$. Inter alia, collaborative wildlife management promises to promote benefit sharing with local communities, collective designing of conservation measures, establish accountability in wildlife conservationand fair property rights in line with principles of democratic 
governance [7, 28]. Current management shift towards collaborative wildlife conservation is, however, implemented against fierce criticisms against both community management [18, 21] and market based management [28]. According to Hulme and Murphree [18, 19], a community is not a homogenous society as there are a number of conflicts within the community itself. The market approach on the other hand is criticised for enriching individuals who manage wildlife at the expense of local communities that exist in the vicinity of protected areas [7]. Market-community collaborative wildlife management is presented as a tool to escaping the limitations of both the market and community based management. To what extent has collaborative wildlife management achieved this goal is the concern of this paper.

Employing the theory of political ecology, this paper examines the challenges of collaborative wildlife management approach as a solution to effective, efficient and equitable wildlife conservation. Using MajeteWildlife Reserve, the study's crucial questions are; what are the principles guiding collaborative management? To what extent has collaborative management increased benefits of wildlife management to the local communities? To what extent has collaborative management established transparent, accountable and collective wildlife management regime? Lastly, to what extent has collaborative wildlife management established fair property rights? A number of studies have been conducted on wildlife management internationally and locally [20, 21, 28]. However, most of these studies have focused on challenges of state and market management approaches and not purely on collaborative management. In particular, the premise that collaborative management can eliminate the weakness of the market and community-based wildlife management remains largely unexplored. This is the gap that this paper aims to fill.

\section{Conceptualizing Collaborative Wildlife Management}

Collaborative Management is a new form of wildlife management aimed at giving various stakeholdersmanagement, access and user rights of resources found in protected areas [6]. It is a form of partnership in which various stakeholders agree on sharing amongst themselves the management functions, rights and responsibilities for a territory or a set of resources under protected status $[3,6]$. In wildlife management, the agency with jurisdiction over the protected area develops partnership with other relevant stakeholders which specifies and guarantees their respective functions, rights and responsibility over a protected area. Borrini-Feyerabend [6] has identified two versions of Collaborative Management based on the way they operate namely; mild version and strong version. Mild version of collaborative management involves consulting and seeking consensus of all stakeholders involved in the management of protected areas; while strong version of collaborative management involves inclusion of stakeholders in the management board or outright devolution of specific authority and responsibility. Mild version of collaborative management, which is largely the focus of this paper, is concerned with consulting and seeking consensus of all stakeholders involved in the management of protected areas. In the case of wildlife management, identified stakeholders may be chiefs, committee members of CBOs, local communities and private wildlife management companies. These stakeholders represent the community and the market.

\section{Merits and Demerits of Collaborative Approach: Theoretical and Empirical Perspectives}

Collaborative management is, justified based on its perceived social, political and economic benefits. Social benefits are mainly concerned with the best approach in reducing hostility, organizing and implementing development activities. On the other hand, economic benefits areseen in terms of redistribution of resources earned in protected areas to the community members. These benefits are meant to cover conservation costs incurred by communities in the process of conserving wildlife and include use of resource found in protected and income from marketing products from the protected area. The major political benefit of collaborative wildlife management centres on giving the local community the opportunity to take part in decision making relating to the wildlife management $[1,9]$. Political benefit of collaborative management is perceived as a means towards creating a more democratic and participatory society through supporting institutionalization of good and democratic governance [6]. Good governance is the creation of proper law and order, elimination of unnecessary government interference and establishment of corrupt free public administration as a means of achieving socioeconomic progress $[13,26]$. Democratic governance on the other hand refers to the recognition of political, civil rights and citizen participation as basic values and development ends in themselves [30].

Equally important, collaborative management lessens the burden of the agency in charge especially when thereiseffective sharing of responsibilities among all the parties involved in the agreement $[6,8]$. This is so as various stakeholders take an active role in ensuring that wildlife and resources from particular protected area are safe. The approach also increasesmanagement effeciency as a result of harnessing different stakeholders' knowledge, skills and capabilities. Collaborative management also tend to fend off resource exploitation from non-local interests which is often the main threat to wildlife conservation. Besides reducing expenses due to voluntary compliance, increased trust among stakeholers promotes stakeholders commitment towards the achievement of conservationgoals. Thus, there is high potential for achievement of conservation goals as all parties actively take part in restricting illegal use of wildlife 
resources by outsiders $[6,25]$.

The greatest support for collaborative wildlife management is that it opens up material benefits to local people in exchange for the costs which they incur in the process of conserving wildlife $[6,14]$. This is achieved by establishing benefit sharing-scheme in which part of the money earned in protected areas is distributed to the members of the communities. Equally important, there is continued access to forest products, meat products and income generation activities.

Notwithstanding theoretical arguments for collaborative management, increased literature has shown that collaborative management is not a panacea to all challenges of wildlife management. First, collaborative management has inherent theoretical flaws in accounting for its benefits, especially when applied to developing countries $[6,8]$. Collaborative management is also not cost-effective as less revenues earned in protected area are distributed among community members. This is so as revenues raised from marketing wildlife related services and products are not enough to meet the cost of operation as well as distribute to the community.

The political and social benefits of collaborative management are also complicated by conditions within developing countries. This is so as high poverty levels in most countries make stakeholders that are not in control of resources subordinate to those in control of resources. Such an arrangement propagate decisions that are promoted by one group. Again, stakeholders in control of resources may be unwilling to equally share authority and responsibility with other stakeholders. At times, some stakeholders may accept inclusive participation at face value but ignore vital aspects of power, interests, history, justice, legitimacy, social difference and scale $[20,25]$. This situation technically reduces the other stakeholders to subordinatesor mere spectators.

Generally, collaborative management requires substantial investment of time, financial and human resources. As such high financial costs are incurred in the preparatory phase and in the process of developing the agreement hence draining resources which would have been used in conservation [6]. It is this situation which led to donor fatigue and withdrawin wildlife conservation as they lose a lot of resources before perceivable outcomes in wildlife management. Normally, donor community subscribe to short term project with specific deliverable outcomes and this may not be suitable for conservation initiatives.

\section{Theoretical Context}

\subsection{Background to the Case Study: The Context of Wildlife Conservation in Malawi}

Malawi has a long history of strong state intervention into wildlife management through the fence and fine approach that was aimed at outlawing traditional methods of hunting which were seen as wasteful in the hunting of game $[10,18]$.
For instance, 1954 Malawi's Game Rules under section 46prohibited any person from using or keeping in possession any hunting weapon. This was against the fact local communities at that time sustainably hunted wild game [12, 16]. However, a plethora of conflicts over wildlife conservation between local communities and conservationists rendered fences and fine approach to wildlife management ineffective and inefficient and was responsible for the shift from state-centered wildlife conservation approach to community-based wildlife conservation approaches [18]. In addition to this, policy shift in wild game conservation was driven by the failure of tourism to generate adequate foreign exchange to sustain itself and dwindling budgetary support to the sector [27]. Thus, the history of wildlife management in Malawi, and many other developing countries, reveals that conflict has been at the centre of interaction between the state and the local communities $[10,16,17]$.

Thus, the most debatable aspect of wildlife management is whether market-community collaborative management can address the shortfalls of the state, communityand market wildlife approaches. This debate recognises that there are not only different interests among different wildlife stakeholders, but also that their interests manifest differently under different management regime. In Malawi, the major actors who have evolved over the history of wildlife conservation, include the state, private companies, civil society, local elites and local communities $[15,14,27]$. International organization such World Bank, World Conservation Union, International Union for Conservation of Nature (IUCN), World Wildlife Fund and World Resource Institute also play a major role in wildlife conservation. Locally, Wildlife Environmental Society of Malawi (WESM) formerly called Nyasaland Fauna Preservation Society is the major NonGovernmental Organisation involved in wildlife management.

Generally, wildlife conservation is favoured by the state, international and local NGOs, local elites and private companies. Most local communities are generally opposed to wildlife conservation [11, 27]. Thus, the most debatable aspect of collaborative management in Malawi is whether theapproach will manage to address the shortfalls of both state and market management.

\subsection{Political Ecology Concept}

It is against the backdrop that wildlife management in Malawi has been characterised by conflicts that this study adopts the theory of political ecology. Political ecology concept defines the environment as an arena where different social actors with asymmetrical political power compete for access to and control over natural resources [29]. The main argument of political economy concept is that uneven power relations among social actors lead to the powerful group determining access to, control and usage of resources. Consequently, there is unequal sharing of resources as decisions pertaining to the resource use are made by powerful actors, who formulate them to their advantage [29]. In the case of this study, there is likely asymmetrical power 
and conflict between the state, conservation activists and private company managing Majete Wildlife Reserve on one hand and local communities surrounding the reserve on the other hand. Political economy concept is, thus, very relevant to this study as wildlife management potentially results in conflicts over access to, and control over, game and other natural resources among different actors. This is so as the game reserve present a livelihood asset (game and other natural resources such grass and shrubs) to local communities; andrevenue and incometo the state and private companies. Furthermore, conservation brings in a lot of opportunity costs to the local communitiesthrough destruction of their crops by wild game. Therefore, the success of collaborative management depends on the extent to which these contested interests are being amicably allocated, competed and resolved.

\section{Methodology}

The results of this study are based on experiences from Majete Wildlife Game Reserve. The game reserve is located in the southern region of Malawi on the western side of the Middle Shire Valley. Majete Game Reserve was established in 1955 on the area which had high human population due to dimbacultivation practiced in the area (cultivation that takes place along river banks). Thus, like in other countries in Southern Africa, the establishment of Majete followed the eviction and transferring of local people to other areas [see 7, 22]. Majete Game Reserve was considered appropriate for this study because it was the first game reserve in Malawi to adopt collaborative management.

This studyemployed a mixed research approach in which both quantitative and qualitative methodologies were used. The main qualitative methods used in data collection included in-depth interviews, focus group discussion and key informants interviews. Desk study was the main method used in collecting quantitative data which involved reading quarterly and annual reports from African Parks Network (the company that was granted management concession by government) and local CBOs. Quantitative methods largely focused on defining and quantifying the benefits that the local communities get from wildlife conservation while the qualitative methods mainly focused on examining wildlife management principles guiding African ParksNetwork. Generally, qualitative approach is ideal in examining outcomes ofcomplex institutional interactionlike the one under study, especially with reference to the issues of transparency, accountability, collective wildlife management, partnership and fair property rights.

The study conducted 35 in-depth interviews with purposively selected key informants which included Group Village Headmen (GVH), Community Conservation Committees, Wildlife and Environmental Society of Malawi officials (WESM), African Parks officials and government officials. The study also conducted 12 FGDs with community members surrounding Majete Wildlife Reserve. Each FGD comprised of 12 members that were randomly chosen from the community members.

\section{Empirical Findings}

\subsection{Institutional Framework for Collaborative Management at Majete: A Mere Pacification of Local Communities}

Majete Wildlife Reserve is currently managed by African Parks Network (APN) which was given a 25 years management concession by government in 2003. This arrangement is in line with the 2004 National Parks and Wildlife Act, which legalized partnership in wildlife conservation. APN employs a market approach to wildlife conservation arguing that wildlife can pay for its conservation if well managed. According to the granted concession, APN is supposed to involve community members in their management of the reserve. This involves consulting them in issues requiring critical decisions such bringing new fierce animals in the area, and allowing them to access and use some of the resources in the reserve such as grass, fish and reeds. It should, however, be pointed out that the core management of the reserve is in the hands of APN. According to the concession, government is given a percentage of the profits from the revenue generated. Local communities on the other hand benefit indirectly by engaging themselves in income generating activities such as selling food to the visitors in the game reserve.

On the face value, collaborative management seems to respond to the long time criticism thatunless local communities who suffer wildlife conservation are involved, wildlife conservation will not be successful. However, the findings of this study reveals that institutional and management arrangement and practices at Majeteperpetuate marginalization of local communities in wildlife conservation. Firstly, while there is formal and legal partnership between government and APN on the sharing of proceeds, there is no formal or clear agreement between local communities and APN on how benefits are going to be shared. Currently, the understanding is that local communities are encouraged and assisted to engage in income generating activities within the reserve such as selling food to visitors, bee keeping and performing dances. Consultations carried out with local communities revealed that they are not a party to the lease agreement signed between APN and government. The state through local chiefs and community based organisations, however, lure local communities to support collaborative management. Local communities feared that APN is not obliged to honour its promises because there is no legal backing to their promises. This study, therefore, argues that collaborative management have just pacified local people to think that their concerns are being taken into consideration [see 5]. On the contrary, APN and government that are managing and directing management of Majete Wildlife Reserve in line with their interests. These findings demonstrate that while collaborative management has the potential to involve local communities 
in wildlife conservation, uneven power relations among different actors is crucial to defining its ultimate outcomes.

\subsection{Benefits of Wildlife Management to Local Communities: From Resource Access to Market Benefits}

The dominant view upholding collaborative management is that it will result in local communities benefiting more from wildlife conservation through sharing of benefits. Malawi's Wildlife Policy emphatically states that local communities are antagonistic towards wildlife conservation because they have for a long time borne the cost of wildlife conservation but the benefits thereof have largely accrued to the state. Thus, fair distribution of benefits is understood to change communities' antagonism to conservation [14]. However, findings from this study demonstrate that these claims lack credible evidence. According to community consultations conducted at Majete, collaborative management has produced three outcomes which make it hard for all local communities to benefit from wildlife conservation.

Firstly, collaborative management is changing the mode through which local communities are accessing benefits of wildlife conservation from physical access to resource to accessing the market benefits of resource conservation. According to the management concession government granted to APN, local communities are supposed to access a number of natural resources within the reserve such as grass, mushroom, fish and reeds. These benefits are in addition to monetary benefits from income generating activities. However, local communities arecurrently rarely allowed to harvest fish, honey and reeds in thegame reserve. Instead, they are allowed to harvest only grass at specific times arguing that communities are supposed to protect and conserve these and that their harvesting disturbs the animals. The position of APN is that apart from physically accessing the resources from the game reserve, local communities will benefit from wildlife conservation through employment, income generating activities they are engaged in and APNcorporate responsibility.

However, these benefits are age, gender and social group selective. At present, a few group of individuals with capabilities of entitling the benefits have risen to support the management regime. These individuals include: those employed by APN, those selling food and beverages to visitors and local community-based organisation (CBOs) dealing with wildlife conservation. Local CBOs, in particular, are occasionally funded by APN to promote wildlife conservation and community commitment to the cause for wildlife conservation. Another group of individuals that are currently benefiting from collaborative management at Majete are families with school-going children who are provided with educational scholarship. APN Majete Scholarship Scheme started in 2006 and has since then been supporting 80 secondary schools going students every year and around 720 students have benefited from this scheme since its inception. Most of the secondary schools fees range from US\$10 to US\$60, with most paying US\$10 a term.
While there are benefits that some individuals get from current wildlife management approaches, these benefits do not offset the direct conservation costs that the wider communities encounter by sharing space with wildlife at Majete. In particular, local community continue to experience loss of different livelihood platforms of livelihood as evidenced by a comment from one of the old local woman interviewed; "we have lost control over our means of livelihood, but cannot also get employed by APN, we are prevented from accessing resources that we need in our daily subsistence life such as fish, mushroom and honey.". The dominant sentiments coming from the FGDs conducted in the area is that collaborative management has managed to divide the people into two groups namely: those that are now benefiting from current management approach and those that continue to lose under current management. This study reveals that the later are primarily the old, uneducated and those with weak social ties. Thus, collaborative management is pushing vulnerable groups of people that largely depend on physical access to the wildlife reserve into deep abyss of poverty. This is so as these groups of people are not only prevented from physically accessing material resources from the reserve but also lacks necessary skills to get assimilated into the new ways of earning a livelihood i.e. tourism industry. This study argues that collaborative management is slowly changing the mode of entitling benefits from wildlife management in favour of those that support, have skills that matcheswith the market system and engage in activities that support market operations. Consequently, collaborative management is reinforcing the old omnipresent dilemma of market oriented resource management.

This paper argues that collaborative management continues to excludecommunities from accessing the resources and the growing support for the regime among the spotted few is based on the organic access to the benefits of wildlife conservation it has created. Organic access is, however, selective as the means to access benefits isnow enshrined within the market system and only those who get connected to its operations and continued existence benefit. Theoretically, the findingsfrom Majete questions the adequacy of political ecology to explain actors that benefit from natural resource conservation under collaborative management. This is so as the conventional view that the powerful group of people controls resource access contradicts the findings from this study. While local powerful elites continue to benefit from wildlife conservation, it is not the political power per see that defines access, use and control over benefit from wildlife conservation, but ability to align oneself with the market based system. For instance, the findings from Majete reveal that poorest households such as those receiving education scholarshipare able to benefitfrom the market system by aligning themselves with the market system.

Collaborative management of wildlife reserve is heralded as a means for increasing wildlife conservation benefits to the wider community. However, the scenario at Majetepaints a cynical picture on firstly, the extent to which the approach 
can increase the benefit of wildlife conservation to local communities, and secondly, the extent to which the approach can address existing resource inequalities. This is so because collaborative management is not only reproducing the old resource access inequalities, but also redefining the traditional mode by which the vulnerable access resources from the reserve. Instead of physical access to the reserve, monetary flow has become a central way of defining benefits. For instance, less than $1 \%$ of the community population are actively involved in running tourism related businesses. Thismeans current benefits are age, gender and social class selective as only those individuals with skills of market operations do actively participate. To this end, few victims of past management regime benefiting from the current regime have becomeits faithful advocates. However, most community members are unable to benefit from this management regime. Consequently, community-market collaborative management has taken the form of patronage rather than community partnership.

\subsection{Defective Mechanisms for Transparency and Accountability}

Collaborative management is based on making wildlife conservation more effective through involvement of all stakeholders, especially local communities. This involves providing motivation for communities' active participation, appreciation for conservation and promoting collective responsibility. Inter alia, this goal requires instituting clear institutional channels for achieving transparent and accountable management system. Malawi's Wildlife Policy [14], in particular highlight that collaborative management should be guided by the following management principles: availability of institutional framework and legally binding agreements at local level; and use of existing community level institutional structures for collaborative management. Measured against these principles, there is limited and deceptive mechanisms for transparency and accountability at Majete.

In terms of institutional and legal framework, this study found that collaborative management at Majete has no clear institutional framework for the inclusion of local communities in the decision making concerning management of the game reserve. Equally important, there is no formal legal agreement between APN and local communities. Instead, APN uses a number of community institutions depending on its specific needs. For instance, APN mainly uses local CBOs in wildlife conservation advocacyand uses local chiefs in enforcing new rules that are at times heavily contested by the community. A good example is a case where APN used local chiefs to enforce Majete Wildlife Reserve boundary adjustment which was largely against the wishes of the local communities. These findings demonstrate that community involvement in the management of the wildlife at Majeteis not only unclear, but also fragmented, divisive and contradictory. This trend is expected as conceptually "community" is not a uniform concept but a composition of people with different interests, power hierarchy and socioeconomic backgrounds [5, 23, 24]. This study argues that without a clear institutional framework, collaborative management is likely to produce a multiplicity of governance actors and structures for a specific function. In the case of Majete, APN is deceptively using a number of local actors toachieve a defined goal in its favour but not necessarily in the favour of the local community as a whole. A case to support this point is where APN used a mere agreement with local chiefs (who were taken to other national parks for a tour) as justification to enforce extension of the wildlife reserve to customary land that was farmed by the local communities. Generally, this way of doing things leaves local communities not only left voiceless but also divided. This situation is worsened by APN ability to coerce the most vulnerable groups of people through offering educational scholarship i.e. school fees to their children.

Equally important, interviews with local communities revealed that APN is not accountable to the local communities. For instance, contrary to their agreement when collaborative management was being established, community members reported that they are not consulted on the introduction of dangerous animals in the game reserve. Interviews with local chiefs and CBOs leaders also revealed that, though they are informed about the new developments within the reserve, they do not have powers to object APN management decisions. Consequently, they are forced to align themselves with APN management for fear of jeopardizing their relations arguing, "We are supposed to support their management decisions so we cannot openly oppose their decisions".

Thefindings from Majete demonstrates that collaborative management is reinforcing and recreating power relations around market based wildlife conservation. In this process, powerful elites have established reciprocity relations with the less powerful groups in support of wildlife conservation. These findings belie assumptions that collaborative management would result into fair distribution of benefits from wildlife conservation. On the contrary, findings from Majete demonstrate that collaborative management can potentially change power hierarchies that control benefits from environmental conservation. Theoretically, political ecology posits that powerful groups of people in society determining access to, control and usage of resources in favour [29]. Notwithstanding the continued benefits that accrue to the powerful elites within the community, findings from Majete demonstrate that a few poor groups of people in a community such as CBOs can benefit and yield collective power in collaborative management of wildlife. However, the benefit to poor groups of people comes at a cost. Firstly, the poor groups are reduced to mere supporters of the wildlife management regime in exchange for financial support i.e. fees that is given to school going children. Secondly, collaborative management potentially block community physical access to natural resources found in the reserve such as honey, mushrooms, reeds and grass. Instead, the community benefits from financial flows from wildlife conservation. This means collaborative management 
recreates local power around the market system. Thus, organic access (access to the wildlife conservation market system and its benefits) has become more important than physical access (physical access to the resource). These findings, therefore, demonstrate that mere inclusion of community in wildlife management does not solve exclusion of the community from enjoying the benefits of wildlife conservation. On the contrary, it does recreates new community actors that findsbenefit in the new system.

\subsection{Conclusions and Recommendations}

This paper has demonstrated that the solution to inclusive and transparent wildlife management in areas of severe poverty is a complicated one. This is largely so because collaborative management changes the mode by which community members access benefits from wildlife conservation i.e. from physically accessing the resource in the reserve to accessing the benefits of conservation through the market system. Thus, benefits from collaborative management are not automatic. The study findings from Majete reveal that collaborative wildlife management is predominantly a market-oriented activity that reproduces new ways of accessing benefits. To this end, collaborate management is reproducing new actors and entities that sustain the market based conservation principles but effectively limit communities' benefits. Hence, the solution to inclusive and transparent wildlife management cannot be a matter of just fussing two management approaches.

This study underlines the need for examining the political ecology theoretical framework that has long guided unequal distribution of benefit from environmental use and conservation. While it is true that powerful elites continue to benefit from wildlife conservation, this study demonstrates that the poorest and less powerful groups of people may also benefit. However, the shift of benefit from direct material livelihood platforms to non-material livelihood needs may drive the poorest households into abject poverty. Theoretically, these findings calls for more understanding of the context under which different groups of people, especially the poor, may benefit from natural resource conservation. This understanding is paramount to designing successful collaborative management arrangements in developing countries where most poor people depend on natural resources. This paper, therefore, concludes that community-market collaborative wildlife management needs re-defining its institutional arrangement so that the approach transforms from being mere community-private sector patronage to community-private sector partnership.

\section{References}

[1] Abdellatif, M. A., (2003). Good Governance and its relationship to Democracy and economic Development in Governance, Democracy and Economic Development. A Report from the Global Forum III on Fighting Corruption and Safeguarding Integrity, 20-31 May 2003, Seoul.
[2] Adams, J. S. and McShane, T. S., (1992). The Myth of Wild Africa. New York: Norton.

[3] Adams W., and D., Hulme (2001). Community Conservation: Changing Narratives, Policies and Practices in African Conservation, in David Hulme and Marshall Murphree (eds.) African Wildlife and Livelihoods: The Promise and Performance of CommunityConservation. Oxford: James Currey.

[4] African Parks Network (2010). Annual Report, Johannesburg.

[5] Blaikie, P. (2006). Is Small Really Beautiful? Communitybased Natural Resources Management in Malawi and Botswana inWorld Development, 34(11) 1942-1957.

[6] Borrini-Feyerabend (1996). Collaborative Management of Protected Areas: Tailoring theApproach to the Context, Issues in Social Policy, IUCN, Gland Switzerland.

[7] Brockington, D., (2002). Fortress Conservation: The Preservation of Mkomazi Game Reserve in Tanzania (Blooming: Indiana University Press, 2002).

[8] Brockington, D., (1999). Conservation, Displacement and Livelihoods: the consequences of the evictionfor pastoralists moved from Mkomazi Game Reserve in Tanzania, in Nomadic Peoples NS Volume Number 3, Issue 21999.

[9] Elahi, K., and Danapoulos, C. P., (2004). Democracy, Capitalism and Development in Journal of Security Sector Management, Vol. 2 No.

[10] Escobar A., (1998). Whose Knowledge, Whose Nature? Biodiversity Conservation and PoliticalEcology of Social Movements, in Journal of Political Ecology Vol.

[11] Escobar A., (2006). "Difference and Struggle over Natural Resources A Political ecology framework", inDevelopment (2006) 49(3), 6-13

[12] Fairhead, J., and Leach, M. (1995). False Forest History, Complicit Social Analysis: Rethinking Some West African Environmental Narratives in World Development Vol. 23, No. 6 pp 1023-1035.

[13] Grindle, M. S., (2004), 'Good Enough Governance: Poverty Reduction and Reform inDeveloping Countries', Governance: An International Journal of Policy, Administration, and Institutions, vol. 17, no. 4, pp. 525-48.

[14] Government of Malawi (GoM, 2005). Wildlife Policy, Department of National Parks and Wildlife, Lilongwe: Ministry of Tourism and National Parks.

[15] Hayes, G. D. (1977). Guide to Malawi's National Parks and Game Reserves (Nyasaland FaunaPreservation Society.

[16] Hayes, G. D., (1972) Wildlife Conservation in Malawi in Society of Malawi. Journal. 25(2), pp.22-31.

[17] Hayes, G. D., (1957). Mijeti, in Oryx, Vol. 2, No. 5 pp 294298.

[18] Hulme D., and Murphree M., (1999). Policy Arena: Communities, Wildlife and the New Conservation in Africa, Journal of International Development, 11, (1999) pp. 277-285.

[19] Hunter, N. D., "G. D Hayes and the N.F.P.S”, in C., Dudley (1978). Nyala Vol. 5, No. 2, December 1978, Nyasaland Fauna Preservation Society pp. 67-75. 
[20] Kjekshus, H., (1977). Ecology Control and Economic Development in East African History; The Case of Tanganyika 1850-1950 (London: Heinemann pp126-160.

[21] Kideghesho, J. R., (2006). Wildlife Conservation and Local Land Use Conflicts in Western Serengeti, Tanzania, (Norway: NTNU.

[22] Kideghesho J. R., (2008). Who Pays for Wildlife Conservation in Tanzania and Who Benefits? Tanzania: Sokoine University of Agriculture.

[23] Merry, S. E. (1988). Legal Pluralism in Law and Society Review, 22(5).

[24] Ostrom, E. (2000). Private and Common Property Rights. Indiana University, Center forthe study of Institutions, Population and Environmental Change, Indiana.

[25] Quazi, S. A, Bushley B. R., and Miles W. B., (2002). Connecting Communities and Conservation: Collaborative Management of Protected Areas in Bangladesh.

[26] Sharma, S., (2007) Democracy, Good Governance, and Economic Development in Taiwan Journal of Democracy, Volume 3, No. 1: 29-62.
[27] Sherry, B. Y., (1995). The Demise of Elephants of the Middle Shire Valley, Southern Malawi Project No. 94/30/9 of the Fauna and Flora Preservation Society of the United Kingdom. Study carried out in collaboration with the Wildlife Society of Malawi, and the Department of National Parks and Wildife, Lilongwe.

[28] Sullivan, S., (2012). Conservation is sexy! What makes this so, and what does this make? AnEngagement with Celebrity and the Environment, in Conservation and Society.

[29] Vaccaro, I., Beltran. O, and Paquet P. A., (2013). Political Ecology and Conservation Policies: some theoretical genealogies", in Journal of Political Ecology, (2013 Vol. 20), pp. 256-277.

[30] Waheduzzaman, (2010). People's Participation for Good Governance: A Study of Rural Development Programs in Bangladesh, PhD Thesis. Victoria University, School of Management and Information Systems, Faculty of Business and Law.

[31] Zuka, S., (2013). Myths and realities in community management of common pool resources in Malawi:social stratification as a negative side-effect of social capital. Journal of Natural Resources Policy Research. 